\title{
Patient and healthcare professional experiences of the Salford Lung Studies: qualitative insights for future effectiveness trials
}

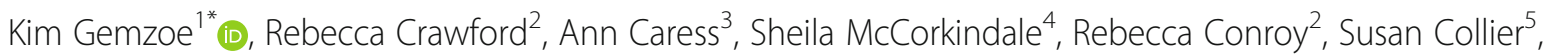
Lynda Doward ${ }^{2}$, Renu M. Vekaria², Sally Worsley ${ }^{6}$, David A. Leather ${ }^{7}$ and Elaine Irving ${ }^{6}$

\begin{abstract}
Background: Randomized controlled trials (RCTs) conducted in the routine care setting provide the opportunity to better understand the effectiveness of new medicines but can present recruitment difficulties. An improved understanding of the challenges/opportunities for patient and healthcare professional (HCP) engagement in clinical research is needed to enhance participation and trial experience. In this study, we explored patient and HCP drivers for, and experiences of, participation in the Salford Lung Studies (SLS), and their views on future trial participation and the overall value of such trials.

Methods: This was a qualitative study set in Salford, UK, comprising patient telephone interviews $(N=10)$ and HCP advisory boards (one with general practitioners [GPs], one with practice managers [PMs]); all individuals had participated in the SLS. Semi-structured telephone interviews were recorded, transcribed and analysed thematically. Advisory board meetings were analysed based on transcriptions of audio recordings and field notes.

Results: For patients, key positive aspects of the SLS were the ease/convenience of study assessments and excellent relationships with study nurses. GPs and PMs considered the SLS to be well-organized and highlighted the value of research nurse support; they also described minor challenges relating to trial systems, initial financial strain on practices and staff turnover. All participants indicated that they were very likely to participate in future trials, citing a design closely aligned with routine care practice as essential. Several strategies to encourage trial participation were suggested, such as clearly communicating benefits to patients and ensuring flexible study assessments.

\footnotetext{
*Correspondence: kim.x.gemzoe@gsk.com

The affiliation "RTI Health Solutions, Manchester M20 2LS, UK" was Dr.

Rebecca Conroy's affiliation at the time of the study and during manuscript preparation.

${ }^{1}$ Real World Study Delivery, Value Evidence and Outcomes, GlaxoSmithKline plc., Research \& Development Ltd., Stockley Park West, 1-3 Ironbridge Road, Uxbridge, Middlesex UB11 1BT, UK

Full list of author information is available at the end of the article
}

(c) The Author(s). 2020 Open Access This article is licensed under a Creative Commons Attribution 4.0 International License, which permits use, sharing, adaptation, distribution and reproduction in any medium or format, as long as you give appropriate credit to the original author(s) and the source, provide a link to the Creative Commons licence, and indicate if changes were made. The images or other third party material in this article are included in the article's Creative Commons licence, unless indicated otherwise in a credit line to the material. If material is not included in the article's Creative Commons licence and your intended use is not permitted by statutory regulation or exceeds the permitted use, you will need to obtain permission directly from the copyright holder. To view a copy of this licence, visit http://creativecommons.org/licenses/by/4.0/. The Creative Commons Public Domain Dedication waiver (http://creativecommons.org/publicdomain/zero/1.0/) applies to the data made available in this article, unless otherwise stated in a credit line to the data. 
(Continued from previous page)

Conclusions: Patients and HCPs had positive experiences of the SLS. The study design, closely aligned with routine care, was considered important to their high likelihood of participating in future trials. The experiences of patients and HCPs in the SLS provide valuable insights that will help inform future best practice in the design and conduct of future real-world effectiveness RCTs in primary care. The detailed first-hand experiences of HCPs will be of significant value to others considering engaging in clinical research and participating in effectiveness RCTs.

Keywords: Salford Lung Studies (SLS), Effectiveness trial, Trial experience

\section{Background}

Effectiveness trials are randomized controlled trials (RCTs) conducted in clinical settings that more closely reflect everyday clinical practice, in patients that more closely represent those to whom the medicine will be prescribed. Such trials provide the opportunity to complement data collected from traditional efficacy RCTs, where clinical settings are idealized and patient populations are highly selected and often represent a minority of the broader patient population eligible for treatment $[1,2]$. However, embedding clinical research into a routine care setting can be challenging with respect to the required infrastructure as well as the impact on treating physicians' time. Furthermore, patients and physicians may already have access to new medicines, so the drive to participate in clinical studies can be low. Successful recruitment often requires extensive resources and significant engagement from healthcare professionals (HCPs) [3].

Previous studies have shown that patient participation in clinical research is associated with factors such as altruism, advancing research, access to new medicines, understanding their own condition, patient circumstances and study design [4-7]. Compared with traditional efficacy trials, effectiveness studies may be less burdensome for patients, making it easier for them to participate. There may be common drivers for patient participation in effectiveness trials and efficacy trials, however, to our knowledge, this has not been confirmed previously.

Relatively little is known about the experiences and engagement of HCPs in clinical research. While physicians may initially express an interest in participating in clinical studies, translation of this interest into actual recruitment of patients may be low [8-10]. Recognized barriers to general practitioner (GP) involvement in clinical studies include resource, physical space, facilities and time requirements, insufficient interest in the research question and disruption to normal clinical practice [11-14]. For patients, a lack of awareness about how clinical research can improve care often results in reluctance, indecision or refusal to participate in clinical trials [15-17]. These challenges underscore the need to better understand the drivers of patient and HCP engagement in clinical research, particularly in the context of effectiveness RCTs.
The Salford Lung Studies (SLS) in chronic obstructive pulmonary disease (COPD) and asthma were world-first, phase III RCTs that evaluated the clinical effectiveness and safety of a pre-licensed medication (fluticasone furoate/vilanterol) in a large population of UK primary care patients [3, 18-21]. To increase engagement of physicians and patients, the SLS team focused on ensuring that the SLS trial design was aligned as far as possible to routine care, with limited study-specific visits, facilitating data collection by providing nurse support for data entry, and enrolling patients at primary care practices with integrated care records to limit the impact on physician time [3]. Patients were managed by their usual GPs and collected study medications where possible from their local participating community pharmacy. All patients received free respiratory prescriptions on-study.

This study used the unique and valuable opportunity provided by the SLS to explore patient and HCPs' perceptions of the value of this type of research, their experiences during the different trial stages and their views on how participation in future effectiveness trials might be improved. This work is of interest to anyone considering engaging with clinical research and participating in effectiveness RCTs and will inform stakeholders looking to improve the design and conduct of future real-world effectiveness studies in primary care.

\section{Methods \\ Study design and participants}

This qualitative study used a qualitative description approach to explore patient and HCPs' (GPs and practice managers [PMs]) experiences of participation in the COPD and asthma SLS [3, 18-21]. Qualitative description is particularly valuable where the intention is to collect information on individuals' experiences in relation to a specific topic and based on what they say [22, 23]. Telephone interviews with patients and advisory board meetings with HCPs in Salford, UK, were conducted to collect data on four key topics: pre-trial experience, experience during the trial, posttrial experience and future trial experience. Interviews/advisory boards were facilitated by an independent not-for-profit research organization (RTI Health Solutions [RTI-HS], Manchester, UK) in collaboration 


\begin{tabular}{|c|c|c|}
\hline & Patients - telephone interviews ${ }^{a}$ & HCPs - advisory boards ${ }^{b, c}$ \\
\hline 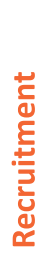 & $\begin{array}{l}\text { - Sponsor invitation letters sent to GP practices }{ }^{d} \text { to } \\
\text { confirm interest } \\
\text { - GP practices identified potential patients and } \\
\text { invitation letters sent } \\
\text { - Patients confirmed interest with GPs and provided } \\
\text { consent to be contacted by sponsor to confirm } \\
\text { participation }\end{array}$ & $\begin{array}{l}\text { - Sponsor invitation letters sent to GP practices }{ }^{d} \text { to } \\
\text { confirm interest } \\
\text { - Project also presented at local networking forums to } \\
\text { raise awareness } \\
\text { - GPs and PMs contacted sponsor to request further } \\
\text { information and confirmed interest in participating }\end{array}$ \\
\hline 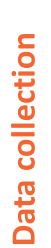 & $\begin{array}{l}\text { - Individual telephone interviews conducted by RTI-HS } \\
\text { researchers ( } 1 \text { hour maximum) } \\
\text { - Semi-structured interview guide used } \\
\text { - Information on patient characteristics captured (e.g. } \\
\text { age, gender, employment status, socioeconomic } \\
\text { status) }\end{array}$ & $\begin{array}{l}\text { - Advisory boards facilitated by three RTI-HS } \\
\text { researchers ( } 3 \text { hours maximum) } \\
\text { - Slide sets prepared to facilitate discussions } \\
\text { - Sample characteristics captured (e.g. gender, } \\
\text { socioeconomic background of location of GP } \\
\text { practice) }\end{array}$ \\
\hline$\frac{\frac{n}{n}}{\frac{n}{\frac{10}{2}}}$ & $\begin{array}{l}\text { - Transcripts produced from audio recordings and } \\
\text { thematic qualitative analysis conducted } \\
\text { - Descriptive summaries created }\end{array}$ & $\begin{array}{l}\text { - Thematic analysis of field notes, supplemented by } \\
\text { review of transcripts from audio recordings } \\
\text { - Descriptive summaries created }\end{array}$ \\
\hline \multicolumn{3}{|c|}{$\begin{array}{l}\text { Fig. } 1 \text { Participant recruitment, data collection and analysis processes. }{ }^{a} \text { Patients were recruited through purposive sampling: GPs that had } \\
\text { participated in the SLS and who had indicated their intention to participate in the qualitative study identified SLS patients and sent them a } \\
\text { patient-centred invitation letter (provided by the sponsor). }{ }^{\mathrm{b}} \text { GPs and PMs were recruited through opportunistic sampling: the sponsor sent an } \\
\text { invitation letter detailing the qualitative study objectives and information about the advisory boards to all GP sites that had participated in the } \\
\text { SLS. 'A single 1-h telephone interview was conducted with a PM who was unable to attend the PM advisory board; this interview was facilitatec } \\
\text { by an interview guide that had been developed based on the PM version of the advisory board slide set. }{ }^{\mathrm{d} T h e} \text { sample of GP practices contactec } \\
\text { was selected to cover a broad range of socioeconomic spread within Salford surrounding areas. }{ }^{e} \text { Analysis conducted using the ATLAS.ti software } \\
\text { (v7.5). Abbreviations: GP, general practitioner; HCP, healthcare professional; PM, practice manager; RTI-HS, RTI Health Solutions; SLS, Salford } \\
\text { Lung Studies }\end{array}$} \\
\hline
\end{tabular}

with the study sponsor (GlaxoSmithKline plc.). RTI-HS and its researchers, who had between 10 and 35 years of research experience, had no relationships with participants and no vested interest in the outcome of the study.

Figure 1 summarizes the participant recruitment process. Opportunistic and purposive sampling was used to recruit HCPs and patients, respectively. Invitation letters were sent by the sponsor to GP practices that had participated in the SLS, providing details of the study and inviting GPs and PMs to take part in the advisory boards. The local Clinical Research Network provided additional support in identifying and contacting PMs. The practice sample was selected to cover a broad range of socioeconomic areas within Salford and Greater Manchester based on the English Index of Multiple Deprivation [24]. GPs who confirmed their interest then identified and contacted potential patients who had participated in the SLS. All participants were reimbursed at fair market value for their time and expenses during the study.

\section{Data collection}

Data collection methods are summarized in Fig. 1. Semistructured telephone interviews with patients, supported by an interview guide focused around the four key topics (Table 1), were conducted by two experienced, independent RTI-HS researchers. Interviews lasted approximately $1 \mathrm{~h}$ and captured patients' views and experiences of the trial process and their suggestions for increasing participation and improving the patient experience. $\mathrm{Pa}$ tient characteristics were collected prior to the start of the interview. Interviews were audio-recorded with patients' permission and later transcribed verbatim and deidentified by a medical transcription vendor (Accuro, Knutsford, UK).

Two separate HCP advisory boards (one with GPs, one with PMs, who had participated in the SLS) were held in Salford, UK. Each advisory board lasted approximately $3 \mathrm{~h}$ and captured HCPs' insights on the operational and 
Table 1 Topics and themes for discussion in patient telephone interviews and HCP advisory boards

\begin{tabular}{|c|c|c|}
\hline Topic & Patient telephone interviews (interview guide) ${ }^{\mathbf{a}}$ & HCP advisory boards (slide sets) ${ }^{\mathbf{b}}$ \\
\hline Pre-trial experience & $\begin{array}{l}\text { - Invitation to participate } \\
\text { - Reasons for participation } \\
\text { - Information about the trial } \\
\text { - Previous research experience }\end{array}$ & $\begin{array}{l}\text { - Reasons for participation }{ }^{c} \\
\text { - Perceived value of participation }{ }^{c} \\
\text { - Positive/negative experiences }{ }^{c} \\
\text { - Challenges and solutions } s^{c} \\
\text { - Engagement of the GP practice and PMs in SLS } \\
\text { - PM views on GP's perceived value of SLS } \\
\text { - Trial preparation, challenges and solutions } \\
\text { - Suggestions for improvements }\end{array}$ \\
\hline $\begin{array}{l}\text { Experience during the } \\
\text { trial }\end{array}$ & $\begin{array}{l}\text { - Positive/negative experiences } \\
\text { - Impact of experience }\end{array}$ & $\begin{array}{l}\text { - Positive/negative experiences }{ }^{c} \\
\text { - Expectations of the trial } \\
\text { - Operational impact of SLS } \\
\text { - Support received for managing the trial } \\
\text { - Challenges and solutions } \\
\text { - Suggestions for improvement }\end{array}$ \\
\hline Post-trial experience & $\begin{array}{l}\text { - Perceived value of SLS } \\
\text { - Trial results } \\
\text { - Missing aspects from SLS }\end{array}$ & $\begin{array}{l}\text { - Views on the process used to share trial results with } \\
\text { GPs } \\
\text { - Perceived value of plain language summary to } \\
\text { patients }{ }^{d} \\
\text { - Suggestions for improvements } \\
\text { - Expectations at end of trial } \\
\text { - Views on receipt of results and dissemination to } \\
\text { patients }\end{array}$ \\
\hline Future trial experience & $\begin{array}{l}\text { - Likelihood of participating in future trials; reasons for and } \\
\text { against } \\
\text { - Suggestions to encourage participation or improve patient } \\
\text { experience } \\
\text { - Views on patient involvement in trial design }\end{array}$ & $\begin{array}{l}\text { - Suggestions to increase GP engagement in future } \\
\text { trials } \\
\text { - Perceptions of research after participation in SLS } \\
\text { - Likelihood of participating in future trials } \\
\text { - Suggestions to improve trial experience }\end{array}$ \\
\hline
\end{tabular}

GP general practitioner, HCP healthcare professional, PM practice manager, SLS Salford Lung Studies

${ }^{a}$ The interview guide was focused on four key topics: pre-trial experience, experience during the trial, post-trial experience and future trial experience. Each section included prompting questions to gather information from patients on specific themes/aspects of the SLS experience

${ }^{\mathrm{b}}$ The slide sets prepared for the GP and PM advisory boards also comprised four key topics: pre-trial experience, experience during the trial, post-trial experience and future trial experience

${ }^{c}$ Content specific to the advisory board with GPs

${ }^{\mathrm{d}}$ Content specific to the advisory board with PMs

logistical experiences during the SLS, their perceived value of this type of research and their views on how participation in future trials might be improved. Three experienced, independent, RTI-HS researchers facilitated the advisory boards using pre-prepared slide sets (Table 1). After spontaneous responses were complete, the facilitators used prespecified prompts to encourage further discussion to ensure that all aspects of the study objectives were explored. RTIHS researchers are trained in the use of prompts to elicit contributions from advisory board participants without influencing the content of their responses. Discussions were audio-recorded with attendees' permission and transcribed verbatim by a medical transcription vendor (Accuro, Knutsford, UK). A single telephone interview was held with a PM unable to attend the advisory board; the interview was conducted using a semi-structured interview guide based on the PM advisory board.

\section{Analysis}

Analysis methods are summarized in Fig. 1. Patient transcripts were reviewed by the research team for accuracy and completeness and underwent thematic qualitative analysis using the ATLAS.ti coding software version 7.5 (ATLAS.ti Scientific Software Development $\mathrm{GmbH}$,
Berlin, Germany). Each transcript was coded by independent primary and secondary researchers for quality control purposes. The initial coding framework was based on the final interview guide. Development of the coding framework was an iterative process with further themes and codes added to the framework during the analysis in order to capture additional information not included by the codes in the initial framework. Descriptive summaries were produced from extracted excerpts relating to codes within each of the four key topics. Analysis of data from the advisory board discussions with GPs and PMs (and the single telephone interview with a PM) was based on transcripts of the audio-recorded meetings and field notes taken by the two independent researchers facilitating the events who recorded their observations directly into an Excel spreadsheet [25]. The field notes were thematically analysed to identify key themes and this information was supplemented by a review of the meeting transcripts.

\section{Results}

\section{Participants}

Ten patients contacted by participating GPs $(n=9)$ agreed to take part in the telephone interviews. Table 2 
presents the characteristics of the 10 patients (three COPD, seven asthma) who participated in the telephone interviews. All patients were White, most (7/10) were male and most $(7 / 10)$ were aged $\geq 55$ years.

Nine GPs attended the GP advisory board: two were based at the same practice, seven were principal investigators and two were sub-investigators during the SLS. Two GPs had practices in the 10\% most deprived areas in England and two had practices in the 10\% least deprived areas.

Six PMs attended the PM advisory board. With one exception, PMs were responsible for a single GP practice and there was little site overlap between GPs and PMs. All GP practices were in areas amongst the $40 \%$ most deprived in England. The single PM interviewed by telephone was from a GP practice in an area amongst the 10-20\% most deprived in England.

\section{Patient experience}

Key themes derived from the analysis of patient interviews are summarized in Table 3 (detailed results in Additional Table 1). Results are presented below as detailed narrative descriptions, with the number of patients whose responses were grouped under each theme also provided. In the pre-trial stage, patients' rationales for participation included: perceived benefit to personal health $(6 / 10)$ or to others $(3 / 10)$, supporting medical science $(5 / 10)$, access to new treatments $(4 / 10)$ and reimbursement $(2 / 10)$. Three patients had minor negative comments regarding the content or length of the study information, but overall, patients regarded the study information as clear and easy to understand:

It was quite explicit; there was a lot of information, but then I think with anything like that, there has to be a lot of information because you have to make informed choices. (Participant 001, female, age range 55-64, asthma)

Patient-reported experience during the trial was largely positive; half of patients had no negative experiences. Patients highlighted the positive relationships with the research nurses $(10 / 10)$, the convenience $(8 / 10)$ and ease (7/10) of study assessments and receipt of free prescriptions $(2 / 10)$ :

Table 2 Characteristics of SLS patients who participated in the telephone interviews

\begin{tabular}{|c|c|c|c|}
\hline & Overall $(\boldsymbol{N}=10)$ & $\operatorname{COPD}(\boldsymbol{n}=3)$ & Asthma $(\boldsymbol{n}=7)$ \\
\hline \multicolumn{4}{|l|}{ Gender, $\boldsymbol{n}(\%)$} \\
\hline Male/female & $7(70) / 3(30)$ & $2(66.7) / 1(33.3)$ & $5(71.4) / 2(28.6)$ \\
\hline \multicolumn{4}{|l|}{ Age, years, $n(\%)$} \\
\hline $18-34$ & $2(20)$ & $0(0)$ & $2(28.6)$ \\
\hline $35-54$ & $1(10)$ & $0(0)$ & $1(14.3)$ \\
\hline $55-74$ & $5(50)$ & $1(33.3)$ & $4(57.1)$ \\
\hline $75+$ & $2(20)$ & $2(66.7)$ & $0(0)$ \\
\hline \multicolumn{4}{|l|}{ General health, $n$ (\%) } \\
\hline Very good & $5(50)$ & $1(33.3)$ & $4(57.1)$ \\
\hline Good & $2(20)$ & $1(33.3)$ & $1(14.3)$ \\
\hline Fair & $3(30)$ & $1(33.3)$ & $2(28.6)$ \\
\hline Poor & 0 & $0(0)$ & $0(0)$ \\
\hline \multicolumn{4}{|c|}{ Other health conditions, $\boldsymbol{n}(\%)$} \\
\hline Yes/no & $9(90)^{a} / 1(10)$ & $3(100) / 0(0)$ & $6(85.7) / 1(14.3)$ \\
\hline \multicolumn{4}{|l|}{ Employment status, $\boldsymbol{n}$ (\%) } \\
\hline Working full-time/retired & $3(30) / 7(70)$ & 0/3 (100) & $3(42.9) / 4(57.1)$ \\
\hline IMD decile (range) ${ }^{\mathbf{b}}$ & $4-10^{c}$ & $9-10$ & $4-10$ \\
\hline \multicolumn{4}{|c|}{ Prior research experience, $n$ (\%) } \\
\hline Yes/no & $5(50) / 5(50)$ & $1(33.3) / 2(66.7)$ & $4(57.1) / 3(42.9)$ \\
\hline
\end{tabular}

COPD chronic obstructive pulmonary disease, IMD Index of Multiple Deprivation, SLS Salford Lung Studies

a Other health conditions included: atrial flutter, benign prostatic hyperplasia, blood pressure difficulties, hay fever, hypertension, hypothyroidism, post-polio syndrome and pulmonary embolism

${ }^{\mathrm{b}}$ The IMD ranks every small area in England from 1 (most deprived area) to 32,844 (least deprived area) and categorizes these into 10 equal groups to determine the deprivation deciles [26]; thus, decile 1 represents the most deprived and decile 10 the least deprived

'Nine patients resided in areas considered to be amongst the $30 \%$ least deprived neighbourhoods in England. One patient resided in an area considered to be amongst the $40 \%$ most deprived neighbourhoods in England 
Table 3 Key themes identified from patient telephone interviews and HCP advisory board meetings

\begin{tabular}{|c|c|c|c|}
\hline Trial stage & Patients $(N=10)$ & GPs $(n=9)$ & PMs $(n=7)$ \\
\hline \multirow[t]{4}{*}{ Pre-trial experience } & Positive & Positive & Positive \\
\hline & \multirow[t]{3}{*}{$\begin{array}{l}\text { - Personal health benefit } \\
\text { - Supporting science } \\
\text { - Access to new treatment } \\
\text { - Altruism }\end{array}$} & $\begin{array}{l}\text { - Financial benefits } \\
\text { - Trial research nurse team } \\
\text { - Patient benefit } \\
\text { - Influence of other participating sites } \\
\text { - Access to hard-to-reach patients } \\
\text { - Sponsor communication/support } \\
\text { - Inclusion and exclusion criteria }\end{array}$ & $\begin{array}{l}\text { - Patient benefit } \\
\text { - Practice financial benefit } \\
\text { - Novel study design } \\
\text { - Access hard-to-reach patients } \\
\text { - Achieve QOF targets } \\
\text { - Elicit large data source }\end{array}$ \\
\hline & & Negative & Negative \\
\hline & & $\begin{array}{l}\text { - Room availability } \\
\text { - Recruitment }\end{array}$ & $\begin{array}{l}\text { - Room availability } \\
\text { - SLS training } \\
\text { - Recruitment } \\
\text { - Data collection process }\end{array}$ \\
\hline \multirow{4}{*}{$\begin{array}{l}\text { Experience during the } \\
\text { trial }\end{array}$} & Positive & Positive & Positive \\
\hline & $\begin{array}{l}\text { - Trial research nurse team } \\
\text { - Study assessments } \\
\text { - Study location } \\
\text { - Free prescriptions }\end{array}$ & $\begin{array}{l}\text { - Expectations met } \\
\text { - Negative pre-conceptions dispelled } \\
\text { - Patient knowledge of condition } \\
\text { - Better quality of care } \\
\text { - Study organization } \\
\text { - Trial research nurse team } \\
\text { - Minimal burden on workload }\end{array}$ & $\begin{array}{l}\text { - Expectations met } \\
\text { - Knowledge from practice nurses } \\
\text { - Patient health improvement } \\
\text { - Study organization } \\
\text { - Minimal impact on practice } \\
\text { - Reduced practice workload } \\
\text { - Sponsor support } \\
\text { - Trial research nurse team }\end{array}$ \\
\hline & Negative & Negative & Negative \\
\hline & $\begin{array}{l}\text { - Not receiving study treatment } \\
\text { - No study results } \\
\text { - Non-participating pharmacies }\end{array}$ & $\begin{array}{l}\text { - Prescriptions } \\
\text { - eCRF system } \\
\text { - Training } \\
\text { - Trial staff turnover } \\
\text { - Recruitment } \\
\text { - Non-participating pharmacies }\end{array}$ & $\begin{array}{l}\text { - Financial burden (e.g. patient } \\
\text { reimbursement) } \\
\text { - Invoice/prescription system } \\
\text { - Trial staff turnover } \\
\text { - Transfer and data storage } \\
\text { - Room availability } \\
\text { - Reporting hospitalizations }\end{array}$ \\
\hline \multirow[t]{4}{*}{ Post-trial experience } & Positive & Positive & Positive \\
\hline & $\begin{array}{l}\text { - Improved knowledge of condition } \\
\text { - Involved in a research study } \\
\text { - Improved inhaler adherence } \\
\text { - Improved symptoms and health }\end{array}$ & $\begin{array}{l}\text { - Treatment effectiveness } \\
\text { - Patient treatment satisfaction } \\
\text { - Willingness to prescribe study drug } \\
\text { - Professional development } \\
\text { - Confidence in research }\end{array}$ & $\begin{array}{l}\text { - High degree of satisfaction } \\
\text { - Expectations surpassed } \\
\text { - Financial benefit invested in the } \\
\text { practice }\end{array}$ \\
\hline & Negative & Negative & Negative \\
\hline & - Did not receive COPD PLS & $\begin{array}{l}\text { - Unaware of COPD results and COPD } \\
\text { PLS } \\
\text { - No incentive to share results }\end{array}$ & $\begin{array}{l}\text { - Unaware of COPD results and COPD } \\
\text { PLS } \\
\text { - Current PLS of low value to patients }\end{array}$ \\
\hline \multirow[t]{4}{*}{ Future trial experience } & Positive & Positive & Positive \\
\hline & $\begin{array}{l}\text { - High likelihood of participating in } \\
\text { research } \\
\text { - Involvement in design of studies }\end{array}$ & $\begin{array}{l}\text { - High likelihood of participating in } \\
\text { research } \\
\text { - Confidence in actively seeking } \\
\text { research } \\
\text { - Involvement in design of studies }\end{array}$ & $\begin{array}{l}\text { - High likelihood of participating in } \\
\text { research } \\
\text { - Increased confidence to participate } \\
\text { - Involvement in design of studies } \\
\text { - Role similar with that in SLS }\end{array}$ \\
\hline & \multicolumn{2}{|l|}{ Negative } & Negative \\
\hline & \multicolumn{2}{|l|}{ - Unlikely to actively seek research } & $\begin{array}{l}\text { - Impact of GDPR implementation } \\
\text { - Unlikely to actively seek research }\end{array}$ \\
\hline
\end{tabular}

COPD chronic obstructive pulmonary disease, eCRF electronic case report form, GDPR General Data Protection Regulation, GP general practitioner, $H C P$ healthcare professional, QOF Quality Outcomes Framework, PM practice manager, PLS plain language summary, SLS Salford Lung Studies

I think my relationship with the nurse that I saw on a regular basis [was a positive experience]. She was absolutely lovely, and I felt very comfortable talking to her... about my asthma and how I was feeling at the time. (Participant 006, female, age range 45-54, asthma)
It was spread out really easy. Like I said, it wasn't like it was every week or they were mithering you in your time... It's hard to turn things down when they make it so easy for you. (Participant 009, male, age range $25-34$, asthma) 
Only three minor criticisms of the experience during the trial were reported. One patient referred to their local pharmacy not being involved, two patients commented on not being randomized to the new study medication and a further two on not receiving the study results:

I would have liked to have been on the trial meds. I just ended up taking the same inhalers throughout... So I think I would have quite liked to have tried the new one just to see if there was any difference, but that's part of being in a study isn't it?... It's the luck of the draw. (Participant 006, female, age range $45-54$, asthma)

My only negative is there being no follow-up to it. It would have been nice if I'd have had a letter from someone on your staff telling me what the results were, how the study was going on... (Participant 002, male, age range 75-84, COPD)

For the post-trial stage, an improved knowledge of COPD and asthma, potential benefits to other people and an interest in receiving the trial results $(6 / 10)$ were articulated by patients:

For me, it was probably making me consider my asthma symptoms a lot more. I can be quite complacent at times, and think I don't need to take my inhalers today and I'm feeling OK; and I think I was a bit more on it while I was on the study. (Participant 006 , female, age range $45-54$, asthma)

All 10 patients reported they would participate in a future study and eight agreed that including patients in the study design phase would be beneficial. Strategies to encourage participation were suggested, such as clearly communicating benefits to patients and flexible study assessments:

You know, make it known, you know, that it is science and that the study is aimed at improving treatments and improving people's health. (Participant 005, male, age range 65-74, asthma)

Everything we did, it was pretty much at our convenience. So I think that's quite an important thing because...people have patterns of their lives and they're busy at different times. So it's just making sure that it's going to fit in with the participant's life and lifestyle. (Participant 001, female, age range 55-64, asthma)

\section{GP experience}

Key themes from the GP advisory board are summarized in Table 3 (detailed results in Additional Table 2). The primary motivation for GPs' decision to participate was financial support, which enabled them to allocate time and resources to the SLS without increasing strain on their practices. GPs had a mainly positive pre-trial experience, notably regarding the provision of research nurse support during study set-up and the nonrestrictive patient recruitment criteria:

The support [of the study nurses] was fantastic. It was really easy because the nurses did it for us to a large degree. And I think without that, if we had to do it ourselves, the remuneration just wouldn't've made sense. (GP, Principal Investigator)

Negative comments focused on issues with patient recruitment, e.g. non-participating pharmacies:

We had a pharmacy that didn't take orders. It was one in one of our deprived [areas], on our patch...they weren't signed up to SLS, so we couldn't recruit any of those patients that were using that pharmacy. (GP, Principal Investigator)

GPs reported a largely positive experience during the trial. The trial was described as well-organized, with good sponsor support, and inclusion of research nurse support was highlighted as a key benefit. Challenges such as recruiting enough patients and prescription errors were mostly resolved internally at GP practices. Although few, negative comments of the trial included safety reporting via the electronic case report form (eCRF) and staff turnover:

There's a lot of safety things I felt didn't need to be reported...I thought it was crazy. I don't know if they have protocols on what you had to capture. It just seemed a bit OTT [over the top] to me, but maybe that's what you wanted. (GP, Principal Investigator)

So you are getting used to how you worked with her [research nurse]... and then they come and another one goes, and you are almost learning the system again because she does it the other way. (GP, Principal Investigator)

Post-trial, GPs considered the value of the trial as largely patient-focused, although some highlighted the professional value of, and increasing their confidence in, participating in research:

It's opened our eyes up a little bit to the possibilities of research as well... We're not frightened of it. (GP, Principal Investigator) 
Despite receiving notifications from the study team, GPs were generally unaware of the trial results. They also did not recall receiving the plain language summary (PLS) of COPD trial findings and were unaware of the plan to disseminate it to patients:

Has there been any mechanism by which plain language summary has been sent to the patients who participated? (GP, Sub-principal Investigator)

All GPs stated that they would be very likely to participate in future trials, but this was dependent on important trial aspects such as a study design similar to the SLS and appropriate financial support. Most important, however, was provision of research nurse support:

As a practice that hasn't got one [research nurse], it would be very important to us that we had. So extra back-up and support, because it just wouldn't be viable for them. (GP, Principal Investigator)

\section{PM experience}

Feedback from the PM advisory board is summarized as key themes in Table 3 (detailed results in Additional Table 3). PMs noted that the final decision to participate in the trial was taken by the GPs, but all had been included in discussions:

I remember there was a team from SLS came and spoke to the entire practice...it was an absolute itinerary of everything that would be expected of practices...we were consulted and we were considered and we were allowed time to think about being involved... (PM, female)

While some issues surrounding room resourcing and complex training were raised, PMs considered involvement in a large trial, potential patient benefit and financial benefit to practices as key drivers of participation and the perceived value of the trial:

...so we'd meet the QOF [quality outcomes framework] targets, and so it would help with our annual reviews and management of those patients throughout the year. (PM, male)

PMs reported mostly positive, but some negative, experiences during the trial. They commented that the trial was well-organized, well-supported, and caused minimal disruption:

It was exactly what we thought it would be and exactly what we were told it would be. There was no surprises; it was exactly what it was. The way we were prepped for it by [the sponsor] was excellent. (PM, male, telephone interview)

Like GPs, PMs considered the research nurses instrumental to successful implementation and participation. However, they also commented on the high nursing staff turnover as well as complex and time-consuming invoicing and prescription systems:

The thing is, once it's [prescription] logged, it's already logged so you had to ring up somebody to get them to delete the one that had been printed. Then you'd have to physically go back in and reissue it...I get why it was like that, I do, but it was a logistical nightmare. (PM, female)

A minor, but notable challenge experienced by practices during the trial related to the initial financial strain of patient reimbursement on practice finances (all patients in the SLS were reimbursed for their time for activities outside of standard care):

We had a float of $£ 500$, I mean, we were only a small practice, smaller group and you were forever having to go and top it up and that was one thing I'll say, keeping a tally of everything we had paid out, claiming was a bit difficult. (PM, female)

PMs expressed a high degree of post-trial satisfaction, surpassing expectations for many. This included seeing clear benefits of the trial for patients and long-term benefits for the practice, e.g. reinvestment of remuneration:

We did invest some monies because we knew we needed more nursing time in terms of [a] health care assistant to alleviate some of the tasks that the nurses didn't need to do... That wasn't as a consequence of the study, that was a bonus, a benefit from the study. (PM, female)

The post-trial dissemination of the SLS results was a minor negative, with most PMs unaware of the published COPD results and COPD PLS. PMs considered the COPD PLS of low value to patients due to its complexity.

Like GPs, PMs expressed a high likelihood of participating in future trials. Key factors in this were research nurse support, and a study design, support and resources similar to the SLS. However, future trials that required the practice to take on roles/responsibilities similar to those that were provided by the SLS support network would not be attractive propositions. PMs noted that the SLS had raised their expectations about participating in future trials. Most PMs indicated interest in providing input on the design of future studies: 
We work in general practice. We know what works in general practice and what doesn't, so, you know, I think it's quite valuable the insight that we would have. (PM, female)

\section{Insights on improvements for future effectiveness RCTs}

Patients were asked for suggestions for overall improvement of future trial experience, while GPs and PMs were asked for their suggested improvements across each of the four main trial stages. Key insights are presented in Fig. 2.

For patients, the main areas for improvement were focused around simplifying study information, the inclusion and training of more local pharmacies, and receiving the study results. Suggested improvements from GPs included a local participating GP testimonial and clearer communication of available resources and support (pre-trial stage), regular principal investigator meetings and improvements to the eCRF system (during the trial), and improving the dissemination of study results (post-trial stage). GPs also suggested including studies as part of a national rewards and incentive programme to increase GP engagement in future trials. PMs suggested a variety of improvements, including tailored training for practice staff (pre-trial stage), improved prescription and invoicing systems (during the trial) and improvements to the study PLS (post-trial stage). To improve the overall experience of participation, PMs suggested their inclusion in the initial study meetings, clearer communication of resources and support, and regular PM meetings during the trial.

\section{Discussion}

Our qualitative approach demonstrated an overall positive experience of participating in the SLS for patients and HCPs. All participant groups highlighted the ease and flexibility of the study assessments and the excellent relationships with study research nurses as being key contributors to the acceptability of this effectiveness study. Minor challenges for HCPs related to data reporting, research nurse turnover, invoicing and prescription systems and patient reimbursement processes. All participant groups indicated a high likelihood of participating in a future trial, with HCPs adding provisos regarding research nurse support and a study design comparable to the SLS. Several strategies to encourage trial participation were suggested, such as clearly communicating benefits to patients and ensuring flexible study assessments.

Typically, RCTs compare an intervention with a clearly defined comparator/placebo under ideal study conditions in a homogenous patient population, such that

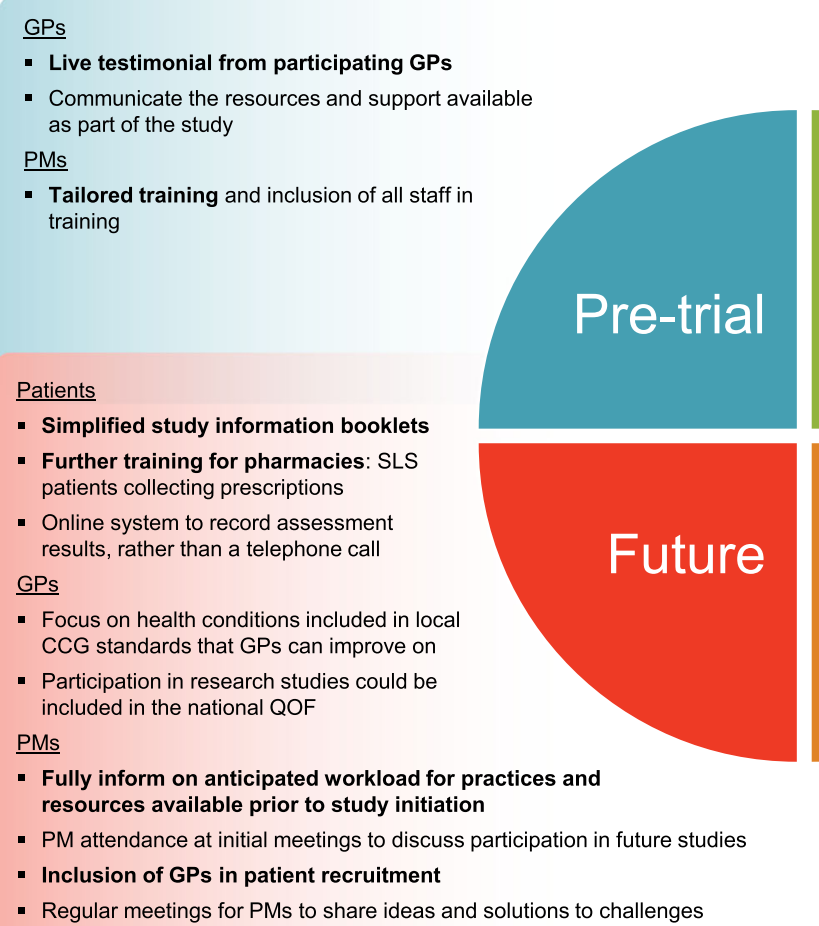

\section{PMs}

- Improve invoicing and prescription ordering system

- Refresher training for systems

- Refine data transfer and storage procedure

- Future studies should mirror SLS design

GPs

- Improve eCRF system

- GP input during study design phase

- Meetings with PIs to discuss SLS challenges/solutions

- Live technical assistance, and refresher training, for systems (e.g., eCRF)

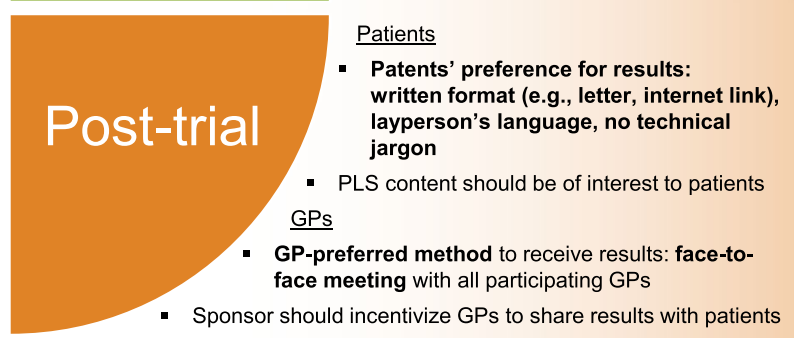

PMs

- PM-preferred method to receive results: e-mail to PMs and PIs

- PM-preferred format for PLS: paper and electronic

- PLS should be a one-page summary with visual content and suitable language

Fig. 2 Summary of main findings regarding suggested improvements for future trials. Bold text indicates improvements considered of more importance. Abbreviations: CCG, Clinical Commissioning Group; eCRF, electronic case report form; GP, general practitioner; GSK, GlaxoSmithKline plc.; PI, principal investigator; PLS, plain language summary; PM, practice manager; QOF, Quality Outcomes Framework; SLS, Salford Lung Studies 
confounders are minimized and rigorous conclusions can be made regarding the efficacy of the intervention $[1,2]$. A major drawback of this approach, however, is the limited ability to generalize results to routine clinical practice, where patients and treatment strategies are vastly more varied. In contrast, real-world effectiveness (pragmatic) RCTs test the effectiveness of an intervention in a much less tightly defined setting, with the aim of providing evidence of whether an intervention actually works in routine clinical practice. Advantages of this approach include the applicability of study results to the wider patient population and utility in comparing complex treatment options.

Despite the growing appreciation of real-world effectiveness RCTs, there are limited data describing the experiences of those participating in them. Previous studies have described the patient experience of recruitment to clinical trials, focusing on patients' decision-making processes in relation to participation, but providing little information on their experiences during the study, their views on future participation or on the value of the study [27]. The findings from this project provide valuable insights from key stakeholders instrumental to the delivery and success of such trials. Trial experiences were collected across a broad range of topics to comprehensively explore the operational and logistical aspects associated with pre-trial, during-trial and post-trial stages of the SLS. To ensure study impartiality, researchers from an independent non-profit research service provider undertook data collection and analysis; this may have allowed participants to more freely express their experiences.

The main limitation of this work was the time elapsed between the end of participants' roles in the SLS and the initiation of this qualitative research (up to 5 years in some cases), which may have affected recall. While the overall sample size $(n=26)$ was comparable with other qualitative research conducted in similar settings using broadly similar methodologies (analysis of semistructured interviews, focus groups, interview transcripts) [28-32], the numbers in each participant group were small. The limited sample of patients $(n=10)$ reflected the difficulty and considerable effort required to re-establish contact with patients and GPs from the SLS. Furthermore, a reduction in the planned number of GPs included in the advisory board from 12 to nine was necessitated by the event coinciding with a particularly busy time of year for GPs in the UK. Our sample comprised only volunteers; those with a poor experience of the SLS may have been less likely to volunteer. The SLS were conducted in a single region in North West England; thus, the socioeconomic spread of our sample was limited, which may affect generalizability. However, this is mitigated by our focus on features of effectiveness trial design and delivery, which are not location-dependent.
There is very limited literature describing the drivers for patient and HCP engagement in effectiveness trials; therefore, this work provides unique and important insights. Consistent with previous research [6], altruism and potential for personal benefits were cited by participants as contributors to their participation in the SLS. Similar to other studies [8, 11, 14, 33], HCPs identified the importance of time and resources required for participation in clinical trials. Our findings add to current knowledge by identifying the provision of good quality research nurse support as essential, both prior to and during the trial. A notable feature of the SLS effectiveness trials, particularly highlighted by PMs, was the minimal disruption to the day-to-day running of practices. Minimizing time commitments, administrative burden and potential conflict with regular clinical duties is important, since these are known barriers to research participation $[9,34]$.

Clearly communicating the value and benefits of trials to patients and HCPs at an early stage is recommended to enhance engagement and participation [35]. The importance of this is illustrated by the observation in this study that patients, GPs and PMs from the SLS all expressed this sentiment as ways in which future trial participation and experience may potentially be improved.

To provide data on effectiveness in conditions closer to routine practice, assessment of outcomes in effectiveness RCTs should interfere as little as possible with standard care [26]. Patients in the SLS commented positively on the ease and convenience of the study assessments, indicating that the trials were successful in this context.

Previous work shows that study participants are very receptive to receiving trial results as aggregate and clinically significant individual results from the trial in which they have participated [36, 37]. Indeed, sponsors are required to provide summary results within 1 year of trial end [38]. As required, disseminating the trial results was a feature of the SLS design, although some patients commented on not receiving the COPD results and GPs and PMs were largely unaware of the results and their role in the dissemination of these. Thus, even with dedicated strategies for dissemination, additional efforts may be required in future trials to ensure the successful dissemination of trial results to patients and HCPs alike.

Patient and HCP engagement and participation in clinical research trials are influenced by a variety of factors that can make recruitment challenging. The success of the effectiveness study approach taken in the SLS is highlighted by patients' positive feedback around the simplicity and convenience of the study assessments, which importantly also extended to the experiences of GPs and PMs, who reported minimal disruption to 
practice day-to-day operations. Moreover, all patients, GPs and PMs who participated in this research reported that they would very likely participate in future trials. This would depend on simple and convenient study assessments from the patient perspective, while the provision of research nurse support was considered essential to the future participation of GPs and PMs. It is notable that patients considered that the benefits of participation, and for GPs and PMs the resources and support available in the trial, need to be more clearly communicated at the recruitment stage. Future effectiveness RCTs could be improved by simplifying study information for patients and ensuring that HCPs are provided with relevant training and have access to userfriendly study systems. Patients and HCPs are also clearly interested in contributing to trial design, a finding noteworthy for sponsors.

\section{Conclusions}

Overall, the experiences of patients and of GPs and PMs show that the overall objectives of the design and delivery of SLS, i.e. minimal disruption to normal care and minimal burden to patients, were successfully met. The experiences of patients and HCPs in the SLS provide valuable insights that will help inform future best practice in the design and conduct of future real-world effectiveness RCTs in primary care. The detailed firsthand experiences of HCPs reported here are a valuable source of information that will be of significant interest to others considering engaging with clinical research and participating in effectiveness RCTs.

\section{Supplementary information}

Supplementary information accompanies this paper at https://doi.org/10 1186/s13063-020-04655-x.

Additional file 1: Table 1. Summary of key findings from the patient telephone interviews. Table 2 Summary of key findings from the GP advisory board meeting. Table 3 Summary of key findings from the PM advisory board meeting.

\section{Abbreviations \\ COPD: Chronic obstructive pulmonary disease; eCRF: Electronic case report form; GDPR: General Data Protection Regulation; GP: General practitioner; HCP: Healthcare professional; IMD: Index of Multiple Deprivation; PLS: Plain language summary; PM: Practice manager; QOF: Quality Outcomes Framework; RCT: Randomized controlled trial; RTI-HS: RTI Health Solutions; SLS: Salford Lung Studies}

\section{Acknowledgements}

The authors thank Jane Squire and Anjum Shah for operational support. Editorial support (in the form of writing assistance, assembling tables and figures, collating author comments, grammatical editing and referencing) was provided by Emma Landers, PhD, at Gardiner-Caldwell Communications (Macclesfield, UK) and was funded by GlaxoSmithKline plc.

\section{Authors' contributions}

$\mathrm{KG}, \mathrm{RCr}, \mathrm{AC}, \mathrm{RCO}, \mathrm{SC}, \mathrm{LD}, \mathrm{RMV}, \mathrm{SW}, \mathrm{DAL}$ and El contributed to study conception and/or design. RCr, RCo, LD and RMV were involved in data acquisition. All authors contributed to data analysis and/or interpretation. All authors contributed to manuscript writing or critical review of draft versions of this manuscript and all approved the final version for submission for publication.

\section{Funding}

This qualitative study was funded by GlaxoSmithKline plc. The Salford Lung Studies were funded by GlaxoSmithKline plc. (studies HZC115151 and HZA115150; ClinicalTrials.gov IDs NCT01551758 and NCT01706198). The funder (GlaxoSmithKline plc.) provided support in the form of salaries for authors KG, SC, SW, DAL and El and provided general feedback on study design. The authors were solely responsible for data collection and analysis and preparation of the manuscript. The specific roles of employees of the study funder are articulated in the 'Authors' contributions' section.

\section{Availability of data and materials}

The anonymized qualitative datasets analysed during the current study and associated documentation may be requested by submitting an enquiry via www.clinicalstudydatarequest.com.

\section{Ethics approval and consent to participate}

According to UK Health Research Authority criteria, this project did not require ethical approval. The project was conducted under GlaxoSmithKline plc.'s Scientific Engagement Policy which enables the non-promotional interaction and exchange of scientific information between GlaxoSmithKline plc. and external communities to advance scientific and medical understanding and improve patient care. Patients, general practitioners and practice managers all provided consent via signed consultancy contracts and were reimbursed for their time at Fair Market Value.

\section{Consent for publication}

Not applicable.

\section{Competing interests}

KG, SC, SW, DAL and El are employees of and have stock/share ownership in GlaxoSmithKline plc. RCr, LD and RMV are employees of RTI Health Solutions, which has received funding from GlaxoSmithKline plc. RCo was employed with RTI Health Solutions at the time of the study and during manuscript preparation. AC and SM declare that they have no competing interests.

\section{Author details}

'Real World Study Delivery, Value Evidence and Outcomes, GlaxoSmithKline plc., Research \& Development Ltd., Stockley Park West, 1-3 Ironbridge Road, Uxbridge, Middlesex UB11 1BT, UK. ${ }^{2}$ RTI Health Solutions, Manchester M20 2LS, UK. ${ }^{3}$ School of Human and Health Sciences, University of Huddersfield, Huddersfield HD1 3DH, UK. ${ }^{4} \mathrm{NIHR}$ Clinical Research Network Greater Manchester, Manchester M13 9NQ, UK. 5UK Medical, GlaxoSmithKline plc, Uxbridge UB11 1BT, UK. ${ }^{6}$ Real World Study Delivery, Value Evidence and Outcomes, GlaxoSmithKline plc., Research \& Development Ltd., Stevenage SG1 2NY, UK. ${ }^{7}$ Global Respiratory Franchise, GlaxoSmithKline plc., Brentford TW8 9GS, UK.

Received: 2 March 2020 Accepted: 5 August 2020 Published online: 17 September 2020

\section{References}

1. Herland K, Akselsen JP, Skjønsberg OH, Bjermer L. How representative are clinical study patients with asthma or COPD for a larger "real life" population of patients with obstructive lung disease? Respir Med. 2005; 99(1):11-9.

2. Woodcock A, Boucot I, Leather DA, Crawford J, Collier S, Bakerly ND, et al. Effectiveness versus efficacy trials in COPD: how study design influences outcomes and applicability. Eur Respir J. 2018;51(2):1701531.

3. New JP, Bakerly ND, Leather D, Woodcock A. Obtaining real-world evidence: the Salford Lung Study. Thorax. 2014;69(12):1152-4.

4. Calamia M, Bernstein JP, Keller JN. I'd do anything for research, but I won't do that: interest in pharmacological interventions in older adults enrolled in a longitudinal aging study. PLoS One. 2016;11(7):e0159664.

5. Canvin K, Jacoby A. Duty, desire or indifference? A qualitative study of patient decisions about recruitment to an epilepsy treatment trial. Trials. 2006;7:32. 
6. Tallon D, Mulligan J, Wiles N, Thomas L, Peters TJ, Elgie R, et al. Involving patients with depression in research: survey of patients' attitudes to participation. Br J Gen Pract. 2011;61(585):134-41.

7. Townsend A, Cox SM. Accessing health services through the back door: a qualitative interview study investigating reasons why people participate in health research in Canada. BMC Med Ethics. 2013;14:40.

8. van Staa TP, Dyson L, McCann G, Padmanabhan S, Belatri R, Goldacre B, et al. The opportunities and challenges of pragmatic point-of-care randomised trials using routinely collected electronic records: evaluations of two exemplar trials. Health Technol Assess. 2014;18(43):1-146.

9. Ledford H. Translational research: 4 ways to fix the clinical trial. Nature. 2011; 477(7366):526-8.

10. Tufts Center for the Study of Drug Development. Impact Report: $89 \%$ of trials meet enrollment, but timelines slip, half of sites under-enroll. 2013; 15(1) Available at: https://static1.squarespace.com/static/5a9eb0c8e2ccd115 8288d8dc/t/5aa2c28fec212d492f36cc8a/1520616079359/Jan-Feb+2013+IR+ summary.pdf (Last accessed 9 Sept 2019).

11. Ross S, Grant A, Counsell C, Gillespie W, Russell I, Prescott R. Barriers to participation in randomised controlled trials: a systematic review. J Clin Epidemiol. 1999;52:1143-56.

12. Raftery J, Kerr C, Hawker S, Powell J. Paying clinicians to join clinical trials: a review of guidelines and interview study of trialists. Trials. 2009;10:15.

13. Rendell JM, Merritt RD, Geddes JR. Incentives and disincentives to participation by clinicians in randomised controlled trials. Cochrane Database Syst Rev. 2007;2:mr000021.

14. Salmon P, Peters S, Rogers A, Gask L, Clifford R, Iredale W, et al. Peering through the barriers in GPs' explanations for declining to participate in research: the role of professional autonomy and the economy of time. Fam Pract. 2007;24:269-75.

15. Oude Rengerink K, Kalkman S, Collier S, Ciaglia A, Worsley SD, Lightbourne $A$, et al. Series: pragmatic trials and real world evidence: paper 3. Patient selection challenges and consequences. J Clin Epidemiol. 2017:89:173-80.

16. Samsudeen BS, Douglas A, Bhopal RS. Challenges in recruiting South Asians into prevention trials: health professional and community recruiters' perceptions on the PODOSA trial. Public Health. 2011;125(4):201-9.

17. Abraham NS, Young JM, Solomon MJ. A systematic review of reasons for nonentry of eligible patients into surgical randomized controlled trials. Surgery. 2006;139(4):469-83.

18. Bakerly ND, Woodcock A, New JP, Gibson JM, Wu W, Leather D, et al. The Salford Lung Study protocol: a pragmatic, randomised phase III real-world effectiveness trial in chronic obstructive pulmonary disease. Respir Res 2015:16:101

19. Woodcock A, Bakerly ND, New JP, Gibson JM, Wei W, Jørgen V, et al. The Salford Lung Study protocol: a pragmatic, randomised phase III real-world effectiveness trial in asthma. BMC Pulm Med. 2015;15:160.

20. Vestbo J, Leather D, Diar Bakerly N, New J, Gibson JM, McCorkindale S, et al. Effectiveness of fluticasone furoate-vilanterol for COPD in clinical practice. N Engl J Med. 2016;375(13):1253-60.

21. Woodcock A, Vestbo J, Bakerly ND, New J, Gibson JM, McCorkindale S, et al. Effectiveness of fluticasone furoate plus vilanterol on asthma control in clinical practice: an open-label, parallel group, randomised controlled trial. Lancet. 2017;390(10109):2247-55.

22. Neergaard MA, Olesen F, Andersen RS, Sondergaard J. Qualitative description - the poor cousin of health research? BMC Med Res Methodol. 2009:9:52.

23. Sandelowski M. Whatever happened to qualitative description? Res Nurs Health. 2000:23:334-40

24. Smith T, Noble M, Noble S, Wright G, McLennan D, Plunkett E. The English Indices of Deprivation 2015 - Statistical Release 30 September 2015. Department for Communities and Local Government. Available at: https:// assets.publishing.service.gov.uk/government/uploads/system/uploads/ attachment_data/file/465791/English_Indices_of_Deprivation_2015_Statistical_Release.pdf (Last accessed 23 Oct 2019).

25. Tessier S. From field notes, to transcripts, to tape recordings: evolution or combination? Int J Qual Methods. 2012;11(4):446-60.

26. Welsing PM, Oude Rengerink K, Collier S, Eckert L, van Smeden M, Ciaglia A, et al. Series: pragmatic trials and real world evidence: paper 6. Outcome measures in the real world. J Clin Epidemiol. 2017;90:99-107.

27. McCann SK, Campbell MK, Entwistle VA. Reasons for participating in randomised controlled trials: conditional altruism and considerations for self. Trials. 2010;11:31.
28. Cheshire A, Ridge D, Hughes J, Peters D, Panagioti M, Simon C, et al. Influences on GP coping and resilience: a qualitative study in primary care. Br J Gen Pract. 2017;67(659):e428-36.

29. Etkind SN, Bristowe K, Bailey K, Selman LE, Murtagh FE. How does uncertainty shape patient experience in advanced illness? A secondary analysis of qualitative data. Palliat Med. 2017;31(2):171-80.

30. Le Roux E, Powell K, Banks JP, Ridd MJ. GPs' experiences of diagnosing and managing childhood eczema: a qualitative study in primary care. Br J Gen Pract. 2018;68(667):e73-80.

31. Sharp T, Malyon A, Barclay S. GPs' perceptions of advance care planning with frail and older people: a qualitative study. Br J Gen Pract. 2018;68(666): e44-53.

32. Stepney M, Aveyard P, Begh R. GPs' and nurses' perceptions of electronic cigarettes in England: a qualitative interview study. Br J Gen Pract. 2019; 69(678):e8-14.

33. Laken MA, Dawson R, Engelman O, Lovelace O, Way C, Egan B. Comparative effectiveness research in the "real" world: lessons learned in a study of treatment-resistant hypertension. J Am Soc Hypertens. 2013;7(1):95-101.

34. Donovan JL, Paramasivan S, de Salis I, Toerien M. Clear obstacles and hidden challenges: understanding recruiter perspectives in six pragmatic randomised controlled trials. Trials. 2014;15:5.

35. Worsley SD, Oude Rengerink K, Irving E, Lejeune S, Mol K, Collier S, et al. Series: pragmatic trials and real world evidence: paper 2. Setting, sites, and investigator selection. J Clin Epidemiol. 2017;88:14-20.

36. Shalowitz DI, Miller FG. Communicating the results of clinical research to participants: attitudes, practices, and future directions. PLoS Med. 2008;5(5): e91.

37. Getz K, Hallinan Z, Simmons D, Brickman MJ, Jumadilova Z, Pauer L, et al. Meeting the obligation to communicate clinical trial results to study volunteers. Expert Rev Clin Pharmacol. 2012;5(2):149-56.

38. European Parliament and Council of the European Union. Regulations: regulation (EU) no 536/2014, clinical trials on medicinal products for human use, article 37. Off J Eur Union. 2014;L158:1-76 Available at: https://ec. europa.eu/health/sites/health/files/files/eudralex/vol-1/reg_2014_536/reg_2 014 536_en.pdf (Last accessed 23 Oct 2019).

\section{Publisher's Note}

Springer Nature remains neutral with regard to jurisdictional claims in published maps and institutional affiliations.

Ready to submit your research? Choose BMC and benefit from:

- fast, convenient online submission

- thorough peer review by experienced researchers in your field

- rapid publication on acceptance

- support for research data, including large and complex data types

- gold Open Access which fosters wider collaboration and increased citations

- maximum visibility for your research: over $100 \mathrm{M}$ website views per year

At $\mathrm{BMC}$, research is always in progress.

Learn more biomedcentral.com/submissions 